\title{
Comparative Analysis of Youth Sexual Behaviour Risks for HIV and AIDS Infection in Mbulu and Mufindi Districts, Tanzania
}

\author{
Bertha, E. Losioki ${ }^{1} \quad$ Eleuther, A. Mwageni ${ }^{2}$ \\ 1.Department of Education, The Mwalimu Nyerere Memorial Academy, Dgtar es Salaam, Tanzania \\ 2.Ardhi University, Dar - es - Salaam, Tanzania
}

\begin{abstract}
The youth are among the vulnerable population for contracting Human Immune deficiency Virus (HIV) and Acquired Immuno deficiency Syndrome (AIDS), which are behavioural related problems. This paper examines sexual behaviour risks for HIV and AIDS infection among youth. A total of 232 youth both in and out of school aged 15-35 years were involved in the study. A cross sectional study design was adopted and data was collected through questionnaire, Non participant observation and documentary review. The study used descriptive statistics to determine frequency, percentages and the mean scores for sexual behaviour risks among the youth in the study areas. The findings showed that more than a half of the sexually active youth had had sexual intercourse and among the youth who had already had sexual intercourse, a half of them did not use condoms. The results showed significant differences in sexual behaviour risks among youth in the study areas $(p<0.05)$. Youth in Mufindi were at a higher risk than was the case with their counterparts in Mbulu. The study call for creation of youth programmes that will focus on reduction of sexual behaviour risks among the youth. Programmes for youth can focus on a range of services including prevention strategies, risk reduction, and behaviour change.
\end{abstract}

Keywords: Youth, Sexual behaviour risks, HIV and AIDS, Infection, prevention, Tanzania

DOI: $10.7176 / \mathrm{DCS} / 9-5-06$

Publication date:May $31^{\text {st }} 2019$

\section{Introduction}

The youth are among the vulnerable population for contracting Human Immune deficiency Virus (HIV) and Acquired Immuno deficiency Syndrome (AIDS), which are recognized as a major public health concern and socio-economic and behavioural related problems in Tanzania. Moreover, despite the prevention efforts the youth encounter and suffer the consequences of considerable risks, particularly those related to sexual and reproductive health such as early sexual debut and unprotected sexual intercourse (Halloway et. al, 2012; NACP, 2012). Furthermore, sexual behaviour risks have health implications such as reproduction, sexually transmitted diseases (STDs) and HIV and AIDS infection (Fehr et. al, 2015; Mir, \& Dwyer, 2011). Evidence shows that increased knowledge about HIV and AIDS does not seem to have any significant relationship with behavioural change. Moreover, it was observed that the youth in Tanzania have high levels of knowledge about HIV and AIDS but have misconceptions about their chances of being HIV infected (Katikiro \& Njau, 2012).

The results of HIV and AIDS and Malaria Indicator survey which was conducted in $2011-12$ indicated that the overall HIV and AIDS prevalence rate among the youth in Tanzania was ( $2 \%)$. This prevalence rate was the same as the one measured in 2007/2008 survey. The survey results indicated further that the percentages of females and males who were HIV positive were (6.6 \% and $2.8 \%)$ respectively (TACAIDS, et. al. 2008; TACAIDS et al. 2013). Furthermore, according to Tanzania HIV and AIDS and Malaria Indicator Survey (2013), for example, (9\%) of females and (10\%) of males aged 15-24 had sexual intercourse for the first time before age 15. In addition, condom use was found to be nearly identical for both female and male (58 \% and 59 \%) respectively (TACAIDS, et. al. 2013).

Moreover, the Tanzania HIV Impact Survey conducted in 2016 - 2017 showed a slight decline of HIV/AIDS infection among youth for example the prevalence among youth aged $20-24$ years was $(3.4 \%)$ among females and $(0.9 \%)$ among males. In addition, for youth aged $25-29$ years the prevalence was $(5.6 \%)$ among females and $(2.3 \%)$ among males. These results suggest a stabilizing HIV epidemic in Tanzania (MoHCDGEC et. al., 2017). However, the surveys showed that youth continued to involve in risk sexual behaviour for example (12\%) of female youth and (13\%) of male youth age $15-24$ had sex before they were 15 
years old. In addition, condom use during premarital sex was found to be low among youth for example only $(37 \%)$ of female and (41\%) of male reported that they used condoms the last time they had sex. Furthermore, HIV/AIDS infection tended to increase with age as youth get involved in sexual activity. It was also found that youth with no education were at a more risk of infections as they initiate sexual activity at a younger age (MoHCDGEC et. al., 2016). The surveys suggest that youth are still vulnerable to HIV and AIDS infection and female youth are more vulnerable than male youth. The reason for female vulnerability is low ability in negotiating safer sex due to gender inequality and getting married at a younger age (MoHCDGEC et. al., 2016).

Based on National AIDS Control Programme (NACP) Surveillance Report on HIV and AIDS and STI in the year 2011, there were 4,400 new clients who were HIV positive in Mufindi district; among them 1774 were males and 2626 were females. In addition, among the new infected clients 2588 were the youth aged between 15 and 34 years. Furthermore, there were 238 new clients who were HIV positive in Mbulu, among these 97 were male and 141 were female. In addition, there were 171 new infected clients aged between 15 - 34 years (NACP, 2011). Moreover, TACAIDS et al. (2013) and NACP (2011) showed that Mbulu and Mufindi districts differ on the levels of new infections and clients aged between 14- 34 account for almost the half of all new infection. This suggests that youth are at a high risk of HIV and AIDS and other STIs infection compared to other age groups. Since HIV infection is the result of human behaviour, behavioural change has been essential in the efforts towards curbing the spread of the infection (Wight et.al. 2012).

This study investigated sexual behaviour risks for HIV and AIDS infection among the youth in order to find out sexual behaviour types that increase youth vulnerability for HIV and AIDS infections. Mufindi District had the highest number (15.7 percent) of people with positive HIV status of all other districts in Iringa region. Furthermore, Mbulu district had the lowest number (0.66 percent) of people with positive HIV status of all other districts in Manyara region (TACAIDS, et. al. 2013). Understanding of risk behaviour in the study area is important for prevention strategies. In addition, it helps to improve the life and social wellbeing of the youth who are among the vulnerable groups. Therefore, the study contributes in addressing HIV and AIDS prevention among the youth as one of the key areas in The Youth Decade Plan of Action (YDPA) 2009-2018, National Youth Development Policy and National HIV Policy (URT, 2001; AU, 2011; URT, 2007).

\section{Materials, Methods and Techniques \\ 2.1 Description of the study}

The study was conducted in Mbulu and Mufindi. Mufindi is located in the Southern Highlands of Tanzania. According to URT (2010), agriculture is the main economic activity followed by small livestock keeping. The area had 66,058 households with an average of 4.2 household size (URT, 2013). Polygamy was common among the Hehe which is the dominating tribe. Initiation ceremonies are practiced for both boys and girls (Redmayne, 1968). Mbulu district is located in the northern part of Tanzania. According to URT (2010) the major economic activities in Mbulu include agricultural and livestock production which accounts for about $90 \%$. The average growth was $3.8 \%$ per annum. The average household size was 6.0 persons (URT; 2013). There are two main ethnic groups, the Iraqw and Datoga. Initiation into manhood and womanhood is practiced as an entrance to adulthood and marriages are arranged by parents (Thornton, 1980).

\subsection{Research Design}

The study adopted a cross sectional study design and the data was collected at once. The major purpose of a cross sectional study is to estimate the prevalence of the outcome of interest for a given population at one point in time (Babbie, 2010). Both quantitative and qualitative approaches were used where questionnaire, Documentary Review and Non participant observation methods were used to obtain primary and secondary data.

\subsection{Study population, Sampling procedures and sample size}

The target population for this study was all the youth who are in school and out of school in Mufindi and Mbulu districts aged between 15 and 35 years. Purposive sampling method was used to select two regions from where two districts were picked purposively. Two wards were selected purposively from each district, depending on location and accessibility. Then one village was picked purposely from each ward. Youth were then selected randomly from 12 households. A total of 232 youth both in and out of school aged 15-35 years were involved in 
the study.

\subsection{Data Analysis}

Data were coded and analysed using the statistical package for Social Sciences (SPSS). Descriptive statistics was used to determine frequency, percentages and the mean scores for sexual behaviour risks among the youth in the study areas. Moreover, before the mean scores were determined, seven (7) variables measuring sexual behaviour risks were computed to form a single variable for total sexual behaviour risks. The variable was abbreviated as TSEXBEHAV. The variables measuring sexual behaviour risks had a good internal consistency, with the Cronbach alpha coefficient of 0.7 which was acceptable (George and Mallery 2003). The maximum score for sexual behaviour risks for each respondent was seven while the minimum was 0 .

Furthermore, the study used an index in order to establish whether the youth in the study areas were involved in low, medium, or high- risk sexual behaviours. The variable (TSEXBEHAV) was used to form and categorize sexual behaviour into an index. A categorical Index of sexual behaviour was considered to be of more practical than a continuous score; therefore, the responses were categorized into three groups as follows; low risk with scores ranging from 0 to 2 , medium risk with scores ranging from $3-4$, and high risk with scores ranging from $5-7$. Moreover, the study used the independent sample $t$ - test in order to determine whether there were differences in the two study areas on the variables under study. Chi square test of independence was used to examine the types of sexual behaviour risks among youth in the study areas.

\section{Results and Discussion}

\subsection{Socio -Demographic Characteristics of the Youth}

Demographic characteristics of the youth were explained using age, marital status, education and religion of the respondents. The information in Table 1 indicates that the mean age of the youth in the study areas was 23 years. The minimum age of the youth in the study areas was 15 years and the maximum age was 35 years.

The results further show that three quarters $(75.4 \%)$ of the respondents among the youth in Mbulu were not married, whereas a half $(56.1 \%)$ of the respondents among the youth in Mufindi were in the same category as indicated in Table 1.

Table 1: Socio -demographic characteristics of the youth

\begin{tabular}{|c|c|c|c|c|c|c|}
\hline & $\begin{array}{l}\text { Mbulu } \\
(\mathrm{N}=118)\end{array}$ & & & $\begin{array}{l}\text { Mufindi } \\
(\mathrm{N}=114)\end{array}$ & & \\
\hline \multirow[t]{2}{*}{ Age of youth } & mean & $\min$ & $\max$ & mean & $\min$ & $\max$ \\
\hline & $23 \pm 4.125$ & 15 & 35 & $23 \pm 6.404$ & 15 & 35 \\
\hline Education level & $\mathrm{n}$ & $\%$ & & $\mathrm{n}$ & $\%$ & \\
\hline Primary education & 54 & 45.8 & & 60 & 52.6 & \\
\hline Secondary education & 48 & 40.7 & & 39 & 34.2 & \\
\hline High school education & 10 & 8.5 & & 5 & 4.4 & \\
\hline Diploma education & 3 & 2.5 & & 6 & 5.3 & \\
\hline Graduate & 3 & 2.5 & & 4 & 3.5 & \\
\hline \multicolumn{7}{|l|}{ Marital Status } \\
\hline Married, living with spouse & 18 & 15.3 & & 23 & 20.2 & \\
\hline Married, spouse lives elsewhere & 1 & .8 & & 7 & 6.1 & \\
\hline Not married, but living with a partner & 10 & 8.5 & & 16 & 14.0 & \\
\hline Not married & 89 & 75.4 & & 64 & 56.1 & \\
\hline Widowed & 0 & .0 & & 4 & 3.5 & \\
\hline \multicolumn{7}{|l|}{ Religious affiliation } \\
\hline Lutheran & 26 & 11.2 & & 23 & 9.9 & \\
\hline Catholic & 66 & 28.4 & & 57 & 24.6 & \\
\hline Moslem & 17 & 7.3 & & 14 & 6.0 & \\
\hline Pentecost & 9 & 7.6 & & 13 & 11.4 & \\
\hline Other & 0 & .0 & & 7 & 6.1 & \\
\hline
\end{tabular}


Moreover, education among the youth ranged from Primary school to Graduate levels. Education level among the youth was classified into five categories as no formal education, primary school, secondary education, high school, Diploma and graduate. The results show that (45.8\%) of youth in Mbulu had primary school education while (52.6\%) of youth had the same level of education in Mufindi. The results also show a slight difference in the attainment of secondary education. The study found that $(40.7 \%)$ of youth had secondary education while $(8.5 \%)$ of youth had high school education in Mbulu. The same trend was noted in Mufindi where $(34.2 \%)$ of the youth had secondary education while less than ten percent $(4.4 \%)$ of youth had high school education. These results suggest that youth in the study areas had lower educational attainment in higher education levels.

Increased educational attainment is particularly important in maintaining one's health because it (education) modifies behaviour which increases an individual's ability to be self-aware and proactive in terms of their health. Individuals with higher education can detect unusual symptoms earlier, seek out information regarding their health and have better coping strategies than is the case with individuals with less than high school education (Mechanic, 2007; UNFPA, 2018). Education level of the respondents in this study therefore had implications in youth sexual behaviour. In addition, more than ten percent (14\%) of unmarried youth were living with a partner in Mufindi. Young people in the same category were less than ten percent (8.5\%) in Mbulu. The study noted further that there was a category of youth who are widowed in Mufindi (3.5\%). Other studies have shown that the socio-economic factors have a strong bearing on individual sexual behaviour as they (socio-economic factors) encourage risky sexual behaviour, especially among young girls (Mmari \& Sabherwal, 2013).

\subsection{Sexual Behaviour Risks among Youth}

Regarding sexual behaviour risks, the information in Table 2 shows that more than a half (63.5\% and 67.2\%) of the youth in Mbulu and Mufindi respectively had lived with a sexual partner. Furthermore, early sexual debut among the youth was noted in the study areas. Moreover, the proportion of youth involved into early sexual debut was higher and significant at $\mathrm{p}<0.05$ in Mufindi than was the case in Mbulu. Data in Table 2 show youth sexual behaviours risks.

Table: 2 Sexual behaviours risks among youth

\begin{tabular}{|c|c|c|c|c|c|c|c|c|}
\hline \multirow[t]{2}{*}{ Sexual behaviour } & & \multicolumn{2}{|c|}{ Mbulu(118) } & \multicolumn{2}{|c|}{ Mufindi(114) } & \multirow{2}{*}{$\begin{array}{l}\text { Total } \\
\mathrm{N}\end{array}$} & $\mathrm{N}=\mathbf{2 3 2}$ & \\
\hline & & $\mathrm{n}_{1}$ & $\%$ & $\mathrm{n}_{2}$ & $\%$ & & $\%$ & \\
\hline \multirow{2}{*}{$\begin{array}{l}\text { Ever lived with a boyfriend/girlfriend/ } \\
\text { partner }\end{array}$} & Yes & 73 & 63.5 & 81 & 71.1 & 154 & 67.2 & $\mathrm{n}_{1=115}$ \\
\hline & $\chi^{2}$ & 1.491 & & df 1 & p value & & .222 & $\mathrm{n}_{2=114}$ \\
\hline \multirow[t]{2}{*}{ Early sexual debut } & Yes & 65 & 55.1 & 77 & 67.5 & 142 & 61.2 & $\mathrm{n}_{1=118}$ \\
\hline & $\chi^{2}$ & 3.791 & & df 1 & p value & & $.052 *$ & $\mathrm{n}_{2=114}$ \\
\hline \multirow[t]{2}{*}{ Ever had penetrative sex } & Yes & 76 & 64.4 & 92 & 80.7 & 168 & 72.4 & $\mathrm{n}_{1=118}$ \\
\hline & $\chi^{2}$ & 7.707 & & df 1 & p value & & $.006 *$ & $\mathrm{n}_{2=114}$ \\
\hline \multirow[t]{2}{*}{$\begin{array}{l}\text { Had sexual intercourse in the past } 12 \\
\text { months }\end{array}$} & Yes & 74 & 62.7 & 80 & 70.2 & 154 & 66.4 & $\begin{array}{l}\mathrm{n}_{1=118} \\
\mathrm{n}_{2=114}\end{array}$ \\
\hline & $\chi^{2}$ & 1.447 & & df 1 & p value & & 0.229 & \\
\hline \multirow[t]{3}{*}{ Use of condoms during sexual intercourse } & No & 62 & 52.5 & 48 & 42.1 & 110 & 47.4 & $\mathrm{n}_{1=118}$ \\
\hline & $\chi^{2}$ & 2.533 & & df 1 & p value & & 0.111 & $\mathrm{n}_{2=114}$ \\
\hline & Yes & 23 & 20 & 43 & 38.4 & 66 & 29.1 & $\mathrm{n}_{1=115}$ \\
\hline \multirow[t]{2}{*}{ Had STI infections } & & & & & & & & $\mathrm{n}_{2=112}$ \\
\hline & $\chi^{2}$ & 9.308 & & df 1 & p value & & $.002 *$ & \\
\hline \multirow[t]{2}{*}{ Having multiple sexual partners } & Yes & 60 & 50.8 & 77 & 67.5 & 137 & 59.1 & $\mathrm{n}_{1=118}$ \\
\hline & $\chi^{2}$ & 6.685 & & df 1 & p value & & $.010 *$ & $\mathrm{n}_{2=114}$ \\
\hline
\end{tabular}

$\mathrm{p}$ value significant $<0.05$ level. $\quad$ Note: $\quad \mathrm{n}_{1}=$ Mbulu; $\mathrm{n}_{2}=$ Mufindi 
The results in Table 2 show that in the past twelve months before the study was conducted, more than a half of the sexually active youth (62.7\% and 66.4\%) had had sexual intercourse in Mbulu and Mufindi respectively. In addition, among the youth who had already had sexual intercourse, a half of them did not use condoms in Mbulu. This suggested that condom use behaviour was low among youth. It was further noted that the youth who had STI infections in Mufindi were almost twice and significant at $\mathrm{p}<0.05$ compared to the youth with a similar problem in Mbulu. The study results also indicated that more than three quarters $(80.7 \%)$ of the youth had ever had penetrative sex in Mufindi while the number was slight lower (64.4\%) in Mbulu. The results are significant at $\mathrm{p}<0.05$. Equally important, the study found out that the youth in the study areas engaged in multiple sexual relationships. The study showed that the youth in Mufindi tended to have more multiple sexual partners than was the case with the youth in Mbulu. These results were found to be significant at $\mathrm{p}<0.05$ showing that sexual behaviour risks differed in the study areas. The results therefore suggested that the youth engaged in risky sexual behaviours and they were at risk of HIV and AIDS and other sexually transmission infections.

These findings concur with other studies for example; a study conducted in Southern highlands of Tanzania revealed that sexually active youth practice risky sexual behaviour with low proportion of condom use ( Njau et.al, 2013). In addition, Ngome (2016) revealed that youth had multiple partners and condom use were negatively associated with consistent use showing that they (youth) were at risk of HIV and other STI's. Moreover, the results confirm that condoms were not consistently used by the youth for various reasons. Firstly, is the fact that the youth sometimes engage themselves into unplanned sexual intercourse, and when condoms are not at their disposal. Secondly, the youth were uncomfortable to obtain condoms from places where it is not convenient to do so, and the third reason is that some parents are so strict that the youth cannot dare to be found in possession with condoms. This suggests that the youth were not free to collect condoms from the areas where adults can see them. The results also suggest that youth sexual escapades are not based on any firm and or honest relationships, and therefore the youth can easily be tempted to engage into other new sexual relationships with little or no knowledge of infection risks. Other studies also showed that different levels of knowledge and misconception about HIV transmission continue to exist among youth (Katikiro \& Njau, 2012; Peter et. al. 2016).

Furthermore, the study further compared the means for sexual behaviour risks. The results show that the means for sexual behaviour risks among male youth were higher in each study area than was the case for female youth. However, both male and female youth in Mufindi were at a higher risk than was the case with their counterparts in Mbulu. Furthermore, when the mean scores in the study areas were compared through an independent sample $\mathrm{t}$ - test, the results showed significant differences in sexual behaviour risks $(\mathrm{t}=4.349, \mathrm{df}=$ $230, \mathrm{p}<.001)$. Table 3 and Appendix 1 summarise the results.

Table: 3 Mean Scores for Risky Sexual Behaviour among the Youth

\begin{tabular}{lllllll}
\hline & Mbulu(n=118) & \multicolumn{5}{c}{ Mufindi(n=114) } \\
\cline { 2 - 7 } & Mean & Min & Max & Mean & Min & Max \\
\hline Male & $3.827 \pm 1.613$ & 1.0 & 7.0 & $5.389 \pm 1.123$ & 1.0 & 7.0 \\
\hline Female & $3.783 \pm 1.757$ & 0 & 7.0 & $4.100 \pm 1.504$ & 1.0 & 7.0 \\
\hline
\end{tabular}

According to the results in Figure 1 a half of the youth in Mbulu were at a lower risk sexual behaviour than was the case with their counterparts in Mufindi. Data in Figure 1 show youth sexual behaviour risks in index groups and their percentage. 


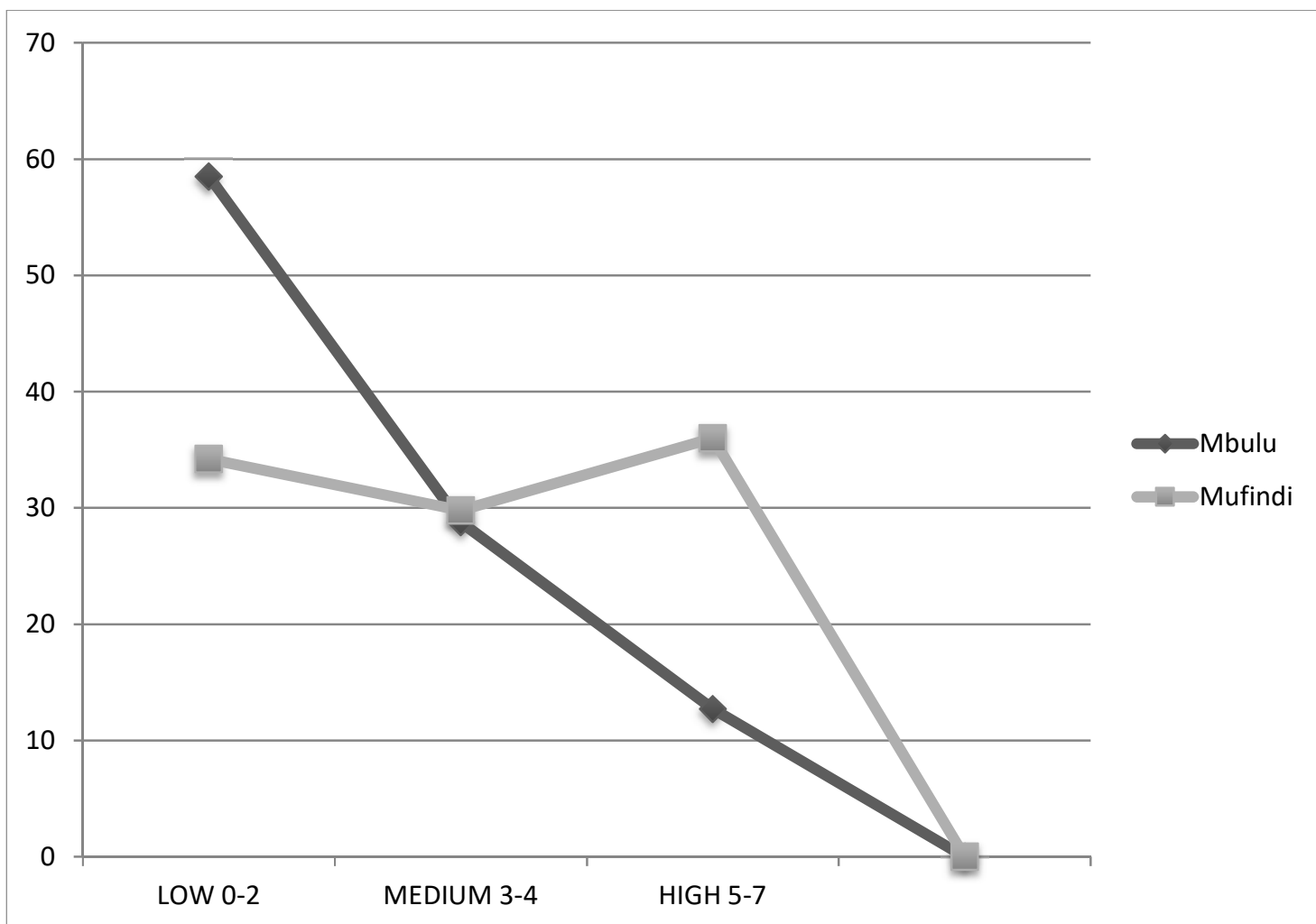

Figure 1:Youth sexual behaviour risks in index groups.

Equally important, the youth in Mufindi were twice as much engaged into high risk sexual behaviours as compared to the youth in Mbulu. These results confirm that the levels of engagement into risk sexual behaviour were different among the youth in the study areas. Other studies have found that the levels of health risk behaviours and the relationship between sexual behaviours and nonsexual risk behaviours may differ in various settings which are socially, culturally, and economically influenced in different ways by the outside world (Tu, Lou et al., 2012).

Moreover, through observation, it was found that in Mufindi, there were various activities that attracted people from outside the area and these included working in tea farms and industries, timber harvesting, processing and selling. It was observed further that there were people coming from other parts of the country for business activities because there were job opportunities in Mufindi that attract people from outside the areas. It was also observed that Mbulu was located in the highland area with no high interaction with people from outside the area unlike the case with Mufindi. Furthermore, there were fewer petty business activities in Mbulu than was the case in Mufindi.

The observed aspects had implications in the lives of the people in the study areas. In addition, there is a well - established association between travels and the acquisition or transmission of STI's (Hamlyn et. al., 2007). It has also been found that the spread of HIV/AIDs, STIs is associated with migrant workforce and petty traders in the borders (Sikira \& Mamuya, 2016). Furthermore, according to MoHCDGEC et. al., (2017), there is a significant variation in HIV prevalence across various regions in Tanzania due to geographical variations where the prevalence ranges from $(11.4 \%)$ in Njombe to less than (1\%) in Lindi and Zanzibar.

\section{Conclusions and Recommendations}

The study findings indicated that sexual behaviour among the youth differed in the study areas. Moreover, youth in Mufindi were at a higher risk than was the case with their counterparts in Mbulu. Furthermore, according to index groups, the findings showed that the youth in the study areas were involved into medium to high risk sexual behaviour. In addition, the youth in Mufindi were at higher risk of contracting HIV and AIDS infections than was the case with the youth in Mbulu. It was also established that not all the youth were using preventive 
measures against HIV and AIDS and STI's infection, a situation which increased their risks of infection. The findings showed further that condoms were not used consistently for various reasons such as accessibility of condoms to the youth because the location and places where condoms were kept were not convenient for the youth to access them. Another reason was strictness of the parents and the fact that the youth engage into unsafe sex.

The study call for creation of youth programmes that will focus on reduction of sexual behaviour risks among the youth. Programmes for youth can focus on a range of services including prevention strategies, risk reduction, and behaviour change. Furthermore, relevant policies should be adopted within the community and/or district that may play a role in strengthening youth programmes.

\section{Acknowledgements}

Thanks are due to Higher Education Students' Loan Board (HELSB) for provision of sponsorship that enabled to undertake the study. The authors also appreciate the availability of data and information from various institutions such as National Bureau of Statistics (NBS), Ministry of Health, Community Development, Gender, Elderly and Children (MHCDGEC), Tanzania Commission for HIV and AIDS (TACAIDS) and National AIDS Control Programme (NACP). 


\section{References}

African Union, (2011). African Youth Decade 2009-2018 Plan of Action: Accelerating Youth Empowerment for Sustainable Development. Addis Ababa: [www.africa- union.org.] Site visited February 2012

Babbie, E. (2010). The practice of social research. 12 ${ }^{\text {th }}$ ed. Belmont: Wadsworth Publishing. $106 \mathrm{pp}$.

Fehr, S. K., Vidouurek, R. A., and King, K. A. (2015). Intra - and inter - personal barriers to condom use among college students: A review of literature. Sexuality and Culture, 19(1), 103- 121.

George, D \& Mallery, P. (2003). SPSS for window step by step: A simple Guide and Reference (4 ${ }^{\text {th }}$ Ed.).

Boston: Allyn and Bacon. 224 pp.

Hamlyn, E., Peer, A., \& Easterbrook, P. (2007). In-depth review on Sexual health and HIV in travelers and Expatriates; In Occupational Medicine 2007; 57:313-321.

Halloway, I.W., Traube, D.E., Schrager, S.M., Levine, B., Alices, S., Watson, J. L., Miranda, A. and Mckay,

M. M. (2012). The effects of sexual behaviour expectancies on early sexual behaviour among urban minority youth. Journal of the Society for Social Work and Research. 3. (1): 1-12.

Katikiro, E. and Njau, B. (2012). Determinant of Behavioural Change for Condom use among out of School Youth in Tanzania. Global Journal of Medicine and Public Health, 1(5): 58-63

Mechanic, D. (2007). Population Health Challenges for Science and Society. The Milbank Quarterly. 85(3) 533 $-559$.

Ministry of Health, Community Development, Gender, Elderly and Children, Ministry of Health [Zanzibar], NBS, OCGS \& ICF (2016). Tanzania Demographic and Health Survey and Malaria Indicator Survey. Dar es Salaam: MoHCGEC, MoH, NBS, OCGS \& ICF. 89-90pp.

Ministry of Health, Community Development, Gender, Elderly and Children, Ministry of Health [Zanzibar],

NBS, OCGS \& ICF (2017). Tanzania HIV Impact Survey. 2016-2017. Preliminary Findings. Dar es Salaam: MoHCGEC, MoH, NBS, OCGS \& ICF. 2pp.

Mir, A.M. \& Dwyer, D. S. (2011). Estimating Peer Effects in Sexual Behavior among Adolescents. Journal of Adolescence 34 (1):183-190.

Mmari, K. \& Sabherwal S. (2013). A Review of Risk and Protective Factors for Adolescent Sexual and Reproductive Health in Developing Countries: An update. Journal of Adolescent Health. 53 (5) 562-572).

NACP - URT (2011). Surveillance Report No. 22, Dar es Salaam: Ministry of social welfare. 86-92 pp.

NACP - URT (2012). National Guideline for management of HIV/AIDS. Dar es Salaam: Ministry of social welfare. 1 pp.

Ngome, E. (2016). Demographic, Socio-Economic and Psychosocial Determinants of Current and Consistent Condom Use among Adolescents in Botswana. Medicine and Health, World Journal of AIDS. 6 (4): 137 156.www.scirp.org/journal. Accessed on August 2017.

Njau, B., Mwakalo, V. \& Mushi D. (2013). Correlates of Use of Condoms among Sexually Active Youth in Southern Highlands Tanzania. Sage Open Journal, 3(2). www.Sagepub.com. Accessed on July 2015.

Peter C.S., Maura, S. and Kim, A. (2016). Developmental Assets and Sexual Reproductive Health among 10- 14 years old in Northern Uganda. International Journal of Child, Youth and Family Studies, 7(1) 45 - 64.

Redmayne, A. (1968). "The Hehe." In Tanzania before 1900. Nairobi: East African Publishing House 37-58pp. TACAIDS, NBS\& ORC Macro (2008). Tanzania HIV/AIDS and Malaria Indicator Survey 2007-2008.

Maryland: TACAIDS, NBS, and ORC Macro. 114 pp.

TACAIDS, NBS, OCGS\&ICF International (2013). Tanzania HIV/AIDS and Malaria Indicator Survey 2011-12. Dar es Salaam: TACAIDS, ZAC, NBS, OCGS\& ICF International. 95pp.

Tu, X.; Lou, C.; Gao, E.; Li, N. \& Zabin, L. S. (2012). The Relationship between Sexual Behaviour and Nonsexual Risk Behaviours among Unmarried Youth in Three Asian Cities in Journal of Adolescent Health 50 (2012) S75-S82 Society for Adolescent Health and Medicine. www.jahonline.org. Accessed on July 2013.

Thornton, W. M. K. (1980). Space, Time and culture among the Iraqw of Tanzania. New York: Academic Press. UNFP (2018). Annual Report, Tanzania. UNFPA. 26pp.

United Republic of Tanzania, (2013). Population and Housing Census. Dar es Salaam: National Bureau of Statistics and Ministry of Finance. $106-194$ pp.

United Republic of Tanzania, (2010). Mufindi District council social economic Profile. MDC. 15pp.

United Republic of Tanzania, (2010). Mbulu District council social economic Profile. MDC.

United Republic of Tanzania, (2007). National Youth Development Policy. Ministry of Labour, Employment and 
Youth Development. 12pp.

United Republic of Tanzania, (2001). National Policy on HIV/AIDS. Dodoma: URT.15 -16pp.

Wight, D., Plummer, M., Ross, D. (2012). The Need to Promote Behaviour Change at the Cultural Level: One Factor Explaining the Limited Impact of the MEMA kwa Vijana Adolescent Sexual Health Intervention in Rural Tanzania. A process Evaluation. BMC Public Health; 12(1):788. 
Appendix 1 Independent Sample t Test

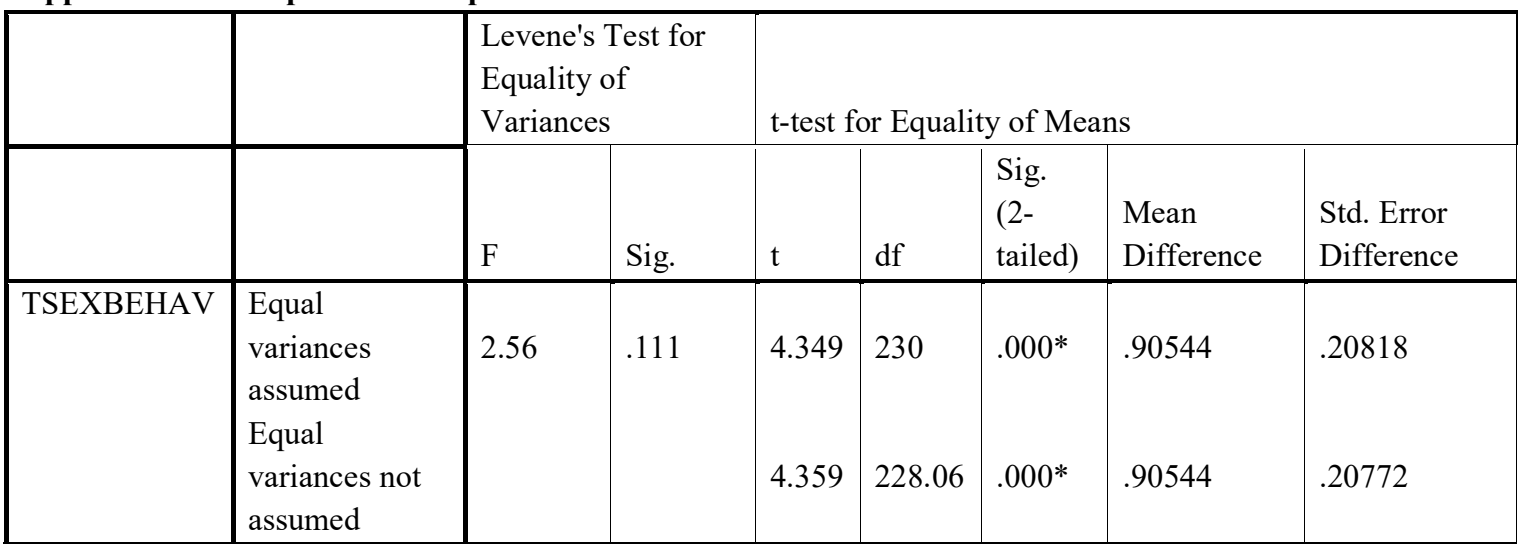

